\title{
PERBANYAKAN STEK PADA TEKNIK PENYIAPAN BAHAN KLONAL GMELINA
}

Cutting Propagation of Gmelina arborea for a Clonal Material Preparation Technique

\author{
J a y u s m a n \\ Pusat Litbang Hutan Tanaman
}

\begin{abstract}
An experiment of clonal material preparation of Gmelina arborea was taken from coppice shoot. Five concentrations NAA (natrium acetid acid) were applied for rooting system technique, namely $0 \mathrm{ppm}$ (control), $400 \mathrm{ppm}, 1200 \mathrm{ppm}, 2400 \mathrm{ppm}$ and $4000 \mathrm{ppm}$ respectively and inserted in a simple technology non-mist propagation system (NMS). The objective of the experiment was to investigate the vegetative propagation of gmelina to determine the appropiate treatment for mass production of clonal planting stock. The result showed that coppice production was $7-15$ coppice/mother tree, survival percentage $(54.3 \%-92.2 \%)$, buds number $(2-2,67)$, leaves number $(15,3-19.67)$, primary roots number $(4.3-9)$, primary roots length $(8.13 \mathrm{~mm}-53.3 \mathrm{~mm})$ and top shoot : roots ratio $(1.62-3.06)$. The result of varians analysis showed that NAA applications had highly significant effect on final survival percentage ( $p=0.001$, ANOVA) with highest value recorded in $2400 \mathrm{ppm}$ NAA treatment. NAA application had no significant effect on buds number, leaves number, primary roots number, primary roots length and top shoot: root ratio.
\end{abstract}

\section{Key words: Clonal, coppice, Gmelina arborea, $N A A, N M S$, Propagation}

\begin{abstract}
ABSTRAK
Percobaan penyiapan bahan klonal Gmelina arborea dilakukan dengan menggunakan coppice (trubusan) dari pohon terseleksi. Teknik pengakaran material stek dilakukan dengan cara penambahan hormon Natrium Acetid Acid (NAA) dengan konsentrasi (0 ppm/kontrol; 400 ppm; 1200 ppm; 2400 ppm dan 4000 ppm) pada media perbanyakan modifikasi sistem NMS - Non Mist System (Longman, 1993) yang merupakan teknologi sederhana tanpa berkabut. Tujuan penelitian adalah untuk menentukan perlakuan terbaik dalam kegiatan produksi masal bahan klonal Gmelina. Hasil percobaan menunjukkan bahwa produksi trubusan sangat baik untuk semua pohon yang diuji ( 7 - 15 tunas per pohon induk). Persentase tumbuh dan berakar stek (54,3\% - 92,3\%), jumlah tunas (2 - 2,67 tunas), jumlah daun stek (15,3 - 19,67), jumlah akar primer (4,3 - 9), panjang akar primer $(8,13 \mathrm{~mm}-53,13 \mathrm{~mm})$ dan nisbah tunas dan akar $(1,62-3,06)$. Hasil analisis keragaman menunjukkan bahwa aplikasi NAA menghasilkan pengaruh yang sangat nyata $(P=0,001)$, dengan nilai terbesar dihasilkan oleh konsentrasi 2400 ppm. Namun secara statistik aplikasi NAA kurang memberikan respon nyata terhadap parameter jumlah tunas, jumlah daun, jumlah akar primer, panjang akar primer dan nisbah pucuk dan akar.
\end{abstract}

Kata Kunci: Gmelina arborea, klonal, NAA, teknik propagasi tanpa pengkabutan, trubusan 


\section{PENDAHULUAN}

Gmelina (Gmelina arborea) merupakan salah satu jenis yang penting untuk hutan tanaman. Jenis ini menyebar secara luas di Pakistan Barat, India Selatan, Nepal, Srilanka, Burma, Thailand, Kamboja, Vietnam dan Cina Selatan. Kayu gmelina dikenal memiliki banyak kegunaan antara lain untuk pulp, veneer, papan partikel, moulding, furniture, kayu lapis. Kayu gmelina memiliki kelas kuat III/IV, kelas awet $\mathrm{V}$ dan relatif konstan pada proses pengeringan. Balfast (1995) melaporkan bahwa sifat pemesinan kayu gmelina sangat baik, sifat penyerutan dan pengampelasan termasuk istimewa dan sifat pembentukannya termasuk baik. Toding (2000) dalam Danu et.al (2001) menambahkan bahwa tanaman G. arborea dapat berfungsi untuk tanaman sekat bakar.

Saat ini pemuliaan pohon telah banyak dilakukan melalui seleksi dan hal tersebut kemungkinan dapat berhasil apabila dilaksanakan melalui implementasi strategi pemuliaan yang efektif. Salah satu teknik yang menjanjikan untuk perbanyakan bahan genetik adalah melalui pemanfaatan propagasi vegetatif. Hartman et.al (1990) dan Sheimbo, (1997) menjelaskan beberapa keuntungan dari perbanyakan vegetatif yaitu (a) keseragaman pertumbuhan, (b) produksi bibit tidak dibatasi musim benih dan (c) bahan tanaman yang dihasilkan memiliki karakter yang sama dengan pohon induk.

Penelitian sebelumnya tentang propagasi vegetatif Gmelina dengan menggunakan stek dari semai telah berhasil dikembangkan (Sipayung, 1993). Uji coba penanaman G. arborea dengan bahan vegetatif dan semai (anakan) memberikan hasil pertumbuhan yang relatif sama hingga tahun ke 4, tetapi bahan tanaman yang berasal dari stek mengindikasikan pertumbuhan tinggi dan diameter yang lebih baik (Danu, et.al, 2001). Yasman dan Leppe (1992) melaporkan bahwa pada percobaan tanaman umur 5 tahun, bahan tanaman dari stek menunjukkan riap rata-rata tahunan (MAI) diameter dan tinggi berturutturut $2,07 \mathrm{~cm}$ dan $4,36 \mathrm{~m}$ serta riap tersebut masih setara dengan tanaman yang berasal dari semai generatif.

Tujuan penelitian ini adalah menelaah perbanyakan vegetatif $G$. arborea untuk menentukan perlakuan yang paling sesuai pada perbanyakan masal bahan klonal. Pengembangan penanaman hutan klonal atau kebun benih klonal gmelina akan dapat dilakukan apabila teknik penyiapan bahan tanaman klonal telah dipahami.

\section{BAHAN DAN METODE}

\section{A. Lokasi}

Penelitian dilakukan di HTI PT Sumatera Tobacco Trade Company (STTC) Kisaran, Propinsi Sumatera Utara untuk pengumpulan materi stek, sedangkan pengujian teknik propagasi stek dilakukan di Persemaian Balai Litbang Kehutanan Sumatera - Pematang Siantar.

\section{B. Bahan dan Alat}

Bahan stek diperoleh dari pohon induk G. arborea dengan profil tinggi $20 \mathrm{~m}-25 \mathrm{~m}$, diameter batang $30 \mathrm{~cm}-45 \mathrm{~cm}$, bentuk batang lurus - silindris, tajuk simetris, percabangan ringan dengan tinggi bebas cabang $9 \mathrm{~m}-14 \mathrm{~m}$, bentuk kulit halus. Hormon pertumbuhan NAA, ruang tanam dan media semai stek memiliki kelembaban $85 \%$ - 90\%. Alat yang digunakan antara lain ice box, gunting stek, knapsack sprayer, hand counter, ember, gelas ukur, thermohigrometer, lightmeter, timbangan analitik, tustel dan alat tulis. 


\section{Prosedur}

1. Stek gmelina berukuran panjang dan diameter bervariasi antara $15 \mathrm{~cm}-20 \mathrm{~cm}$ dan $1 \mathrm{~cm}-3 \mathrm{~cm}$.

2. Hormon pertumbuhan yang digunakan adalah NAA dengan 5 tingkat konsentrasi. Konsentrasi NAA yang diinginkan dibuat dengan melarutkan NAA murni dalam etanol 95\% dan ditambahkan air sesuai konsentrasi yang diinginkan. Untuk setiap konsentrasi NAA dicelupkan 30 bahan stek. Bagian pangkal stek direndam larutan NAA tersebut selama 15 menit.

3. Media semai stek berupa kerikil besar (koral) setebal $10 \mathrm{~cm}$ ditempatkan sebagai lapisan media dalam bak semai berukuran lebar $1 \mathrm{~m}$ dan panjang $4 \mathrm{~m}$, kemudian sarlon (plastic net) sebagai penutup diletakkan di bagian atas media kerikil dan sclanjutnya ditaburkan media pasir halus hingga mencapai tebal $20 \mathrm{~cm}-30 \mathrm{~cm}$. Media semai dilengkapi sungkup dari plastik setinggi $45 \mathrm{~cm}$ sebagai penaung dan pengatur kelembaban. Kelembaban di dalam sungkup diupayakan pada kisaran $85 \%-95 \%$, temperatur tidak melebihi $30^{\circ} \mathrm{C}$ dengan intensitas cahaya berkisar 4000 - 5000 lux.

4. Pengukuran berat kering akar dilakukan dengan cara memotong akar dan mengeringkannya di dalam oven (suhu $60^{\circ} \mathrm{C}$ sampai berat kering konstan), kemudian dilakukan penimbangan dengan timbangan analitik.
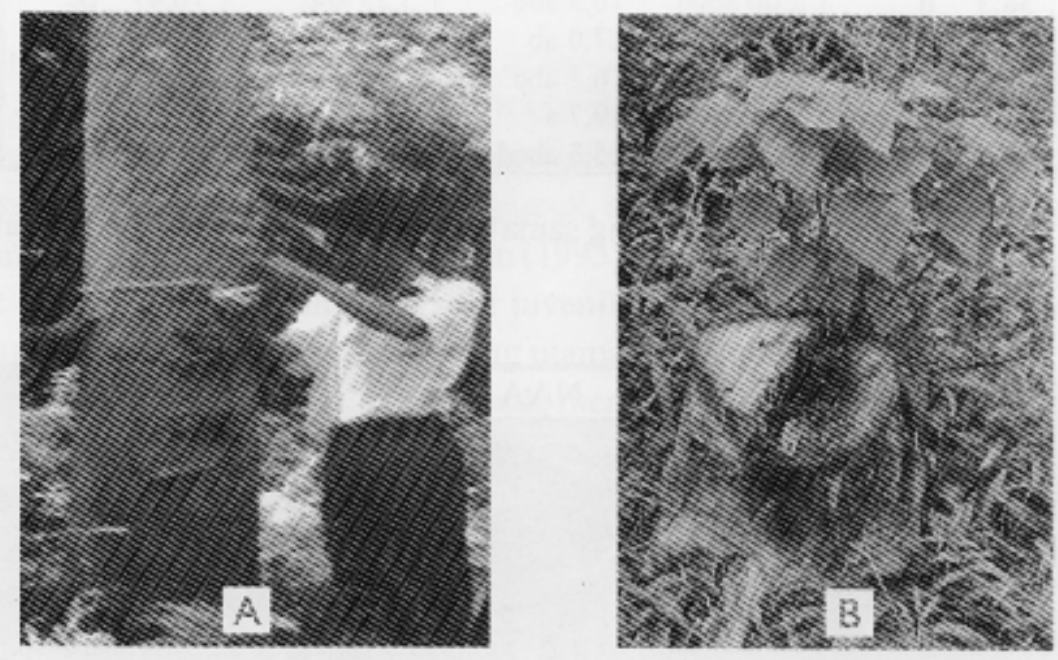

Gambar 1. Keragaan pohon induk gmelina (A) dan trubusan/coppice pohon induk gmelina (B)

\section{Metode Penelitian}

Percobaan ini menggunakan Acak Kelompok dengan 3 ulangan. Bentuk perlakuan konsentrasi NAA yang diuji disusun yaitu: Kontrol ( 0 ppm), 400 ppm, 1200 ppm, 2400 ppm dan 4000 ppm. Tiap kombinasi perlakuan terdiri atas 10 stek, sehingga jumlah stek yang diuji berjumlah $5 \times 10 \times 3=150$ stek. Parameter pengamatan terdiri atas persen stek berakar, jumlah tunas, jumlah dan panjang akar utama dan nisbah tunas dengan akar.

\section{E. Analisa Data}

Hasil pengukuran setiap parameter dianalisis keragamannya (Gomez and Gomez, 1984) dan untuk perlakuan yang menunjukkan perbedaan diuji lebih lanjut dengan menggunakan prosedur DMRT (Duncan Multiple Range Tesi). 


\section{HASIL DAN PEMBAHASAN}

\section{A. Hasil Penelitian}

Hasil percobaan memperlihatkan bahwa konsentrasi NAA 0 ppm (kontrol) memberikan pengaruh paling rendah terhadap persentase keberhasilan perakaran (persen jadi stek), jumlah daun dan panjang akar primer. Semua konsentrasi NAA tidak memberikan pengaruh yang nyata terhadap jumlah tunas dan daun, jumlah dan panjang akar utama serta perbandingan tunas dan akar, tetapi berpengaruh nyata terhadap keberhasilan persentase perakaran/daya hidup dengan konsentrasi NAA $1200 \mathrm{ppm}$ memberikan hasil terbaik dibandingkan konsentrasi lainnya. Rekapitulasi analisis keragaman dan uji lanjutan disajikan pada Tabel 1 dan hasil pengamatan terhadap keragaan stek gmelina disajikan pada Gambar 2.

Tabel 1. Pengaruh konsentrasi N $\Lambda \Lambda$ pada persen jadi stek berakar, jumlah tunas, jumlah daun, jumlah akar primer, panjang akar primer serta nisbah tunas dengan akar stck $G$ arborea.

\begin{tabular}{|c|c|c|c|c|c|c|}
\hline $\begin{array}{c}\text { Konsentrasi } \\
\text { NAA } \\
(\mathrm{ppm}) \\
\end{array}$ & $\begin{array}{c}\text { Persentase } \\
\text { stek berakar } \\
(\%)\end{array}$ & $\begin{array}{l}\text { Jumlah } \\
\text { tunas }\end{array}$ & $\begin{array}{c}\text { Jumlah } \\
\text { daun }\end{array}$ & $\begin{array}{l}\text { Jumlah akar } \\
\text { primer }\end{array}$ & $\begin{array}{l}\text { Panjang akar } \\
\text { primer ( } \mathrm{mm})\end{array}$ & $\begin{array}{c}\text { Nisbah } \\
\text { tunas dengan } \\
\text { akar }\end{array}$ \\
\hline $\begin{array}{l}400 \mathrm{ppm} \\
1200 \mathrm{ppm} \\
2400 \mathrm{ppm} \\
4000 \mathrm{ppm} \\
0 \mathrm{ppm} / \mathrm{kontrol}\end{array}$ & $\begin{array}{l}58,3 \text { d } \\
66,7 \text { c } \\
92,3 \mathrm{a} \\
84,9 \mathrm{ab} \\
54,3 \text { de }\end{array}$ & $\begin{array}{l}2,00 \mathrm{abcd} \\
2,30 \mathrm{abc} \\
2,00 \mathrm{abcd} \\
2,67 \mathrm{a} \\
2,33 \mathrm{ab}\end{array}$ & $\begin{array}{l}16,3 \mathrm{abc} \\
17,0 \mathrm{ab} \\
16,3 \mathrm{abc} \\
19,7 \mathrm{a} \\
15,3 \mathrm{abcd}\end{array}$ & $\begin{array}{l}5,33 \mathrm{abc} \\
5,33 \mathrm{abc} \\
7,63 \mathrm{ab} \\
9,00 \mathrm{a} \\
4,00 \mathrm{abcd}\end{array}$ & $\begin{array}{l}10,47 \text { bc } \\
53,13 \text { a } \\
8,53 \text { cd } \\
12,07 \text { b } \\
8,13 \text { cde }\end{array}$ & $\begin{array}{l}3,03 \text { ab } \\
3,06 \mathrm{a} \\
1,62 \text { abcde } \\
2,00 \text { abc } \\
1,94 \text { abcd }\end{array}$ \\
\hline
\end{tabular}

Keterangan: Tabel yang memiliki huruf yang sama menunjukkan tidak berbeda nyata pada $\mathrm{p}<0,05$ sesuai hasil uji Duncan.

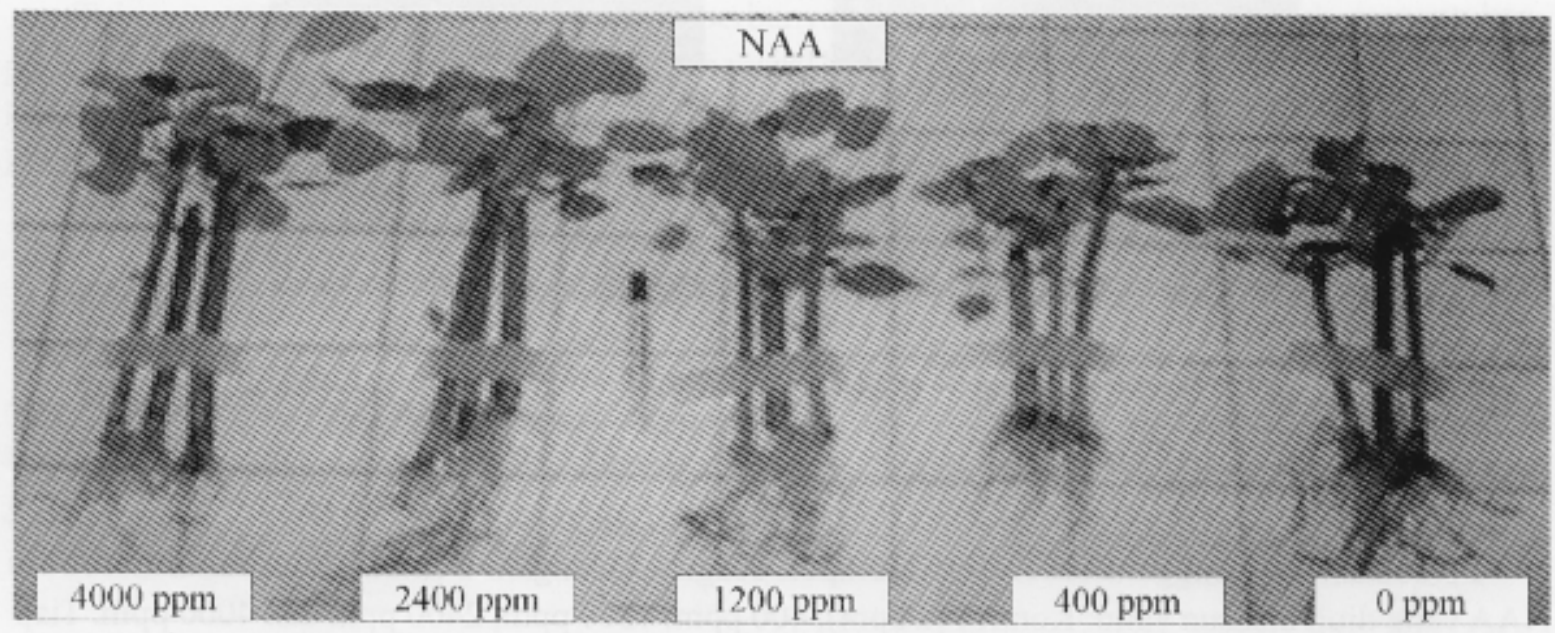

Gambar 2. Keragaan stek gmelina pada beberapa konsentrasi hormon NAA

Kenyataan bahwa persentase perakaran maksimum dari $54,3 \%-92,3 \%$ dihasilkan pada semua perlakuan, hal tersebut menunjukkan bahwa jenis ini dapat diperbanyak dengan menggunakan metode yang sama yang dihasilkan pada jenis Slyrax benzoine Dryand (Jayusman, 1997). Dibandingkan dengan kontrol, persentase perakaran dan parameter lainnya lebih baik dan cenderung meningkat hingga konsentrasi $1200 \mathrm{ppm}$. Hal ini menunjukkan bahwa NAA memiliki interval konsentrasi yang sempit. Siagian et al., (1995) melaporkan bahwa NAA 1000 ppm memberikan keberhasilan perakaran tertinggi pada perbanyakan cangkok jenis Hevea brasiliensis. 
Penemuan sebelumnya menunjukkan adanya ambang penerimaan konsentrasi berbahaya yang sangat dekat dengan konsentrasi optimal untuk pengakaran stek, sehingga aplikasi harus dilakukan secara hati-hati sehingga tidak melewati konsentrasi optimum. Longman (1993) menyatakan bahwa jenis auksin dan konsentrasinya berbeda antara satu jenis dengan jenis yang lain, tetapi konsentrasi optimum akan dapat ditemukan dengan melakukan berbagai percobaan. Permulaan yang baik dapat menggunakan IBA pada konsentrasi 250 ppm hingga 5000 ppm. Perlakuan dengan menggunakan NAA menunjukkan beberapa variasi terhadap persentase keberhasilan perakaran. Beberapa faktor yang diduga menyebabkan terjadinya variasi hasil pengujian adalah :

1. Bahan stek yang diambil diklasifikasikan sebagai stadium juvenil. Salah satu ekspresi fisiologi pada stadium juvenil adalah kemampuan perakaran yang tinggi.

2. Metode barking yang digunakan untuk menumbuhkan trubusan (coppice), mampu memberi kapasitas perakaran yang tinggi dari tunas juvenil dan ini berhubungan dengan produksi auxin (hormon pertumbuhan akar) atau memberikan keseimbangan produksi hormon akar, sehingga penambahan auxin dari luar tidak membuat banyak perbedaan.

3. Penambahan hormon akar pada stek untuk meningkatkan keberhasilan perakaran masih dalam pengujian.

\section{B. Pembahasan}

Hasil penelitian ini menunjukkan bahwa G. arborea mengindikasikan untuk dapat diperbanyak secara vegetatif dengan menggunakan metode NMS (Longman, 1993), hal ini selaras dengan hasil penelitian sebelumnya (Sipayung, 1993), yang menunjukkan bahwa persentase perakaran maksimum $(>70 \%)$ dihasilkan konsentrasi NAA pada stek pucuk, sehingga jenis gmelina ini dapat diperbanyak dengan menggunakan metode vegetatif. Longman (1993) menggambarkan tunas trubusan yang berasal dari kira-kira $2 \mathrm{~m}$ dari tanah biasanya bersifat juvenil (seperti tunas dari kecambah), serta sering menghasilkan tunas segar dengan struktur batang utama yang mudah berakar.

Pemahaman dasar mengapa jenis yang berbeda menghasilkan persentase perakaran yang kontras pada media perakaran yang berbeda tidaklah diketahui secara pasti, tetapi kemungkinan hasil ini berhubungan dengan perbedaan/variasi oksigen, kandungan air, $\mathrm{pH}$ dan porositas dari media. Faktorfaktor ini berpengaruh terhadap respirasi jaringan dan pembelahan sel pada bagian dasar stek dan kemudian diikuti dengan pertumbuhan akar. Percobaan ini menjelaskan adanya keterkaitan kapasitas udara dengan nisbah dan kandungan air. Percobaan menunjukkan bahwa jumlah akar per stek meningkat selaras dengan meningkatnya konsentrasi Auksin, sebagaimana kecenderungan pengamatan pada perbanyakan stek $G$. arborea (Sipayung, 1993). Persentase perakaran dari sejumlah pohon tropis lainnya adalah relatif hasilnya sesuai insentif besarnya penambahan IBA (Indole Butiric Acid) dan IAA (Indole Acetid Acid) dari kelompok hormon auksin disamping NAA (naftaline acetid acid).

Penyebab utama kematian stek adalah busuk stek yang diikuti dengan gugurnya daun. Pembusukan dasar stek berhubungan dengan kelebihan suplai air di jaringan tanaman yang umumnya terjadi setelah daun gugur, sehingga menyebabkan transpirasi terhenti. Untuk mengurangi kematian stek, penanganan yang hati-hati terhadap bahan stek dan pengaturan kondisi iklim tempat stek diperlukan untuk mengurangi terjadinya kekurangan air. Konsentrasi NAA mempunyai pengaruh yang besar tehadap persentase perakaran, penambahan NAA dengan konsentrasi lebih dari 1200 ppm masih diperbolehkan untuk meningkatkan jumlah akar. Namun demikian penelitian lebih lanjut dibutuhkan untuk mengidentifikasi tingkat veriasi genotipe dalam respon perakaran, dimana sebelumnya telah ditemukan berpengaruh nyata pada jenis pohon tropis yang lain (Shiembo, et al., 1997).

Berkaitan dengan produksi trubusan dan menghindari proses penuaan, Longman (1993) menyarankan bahwa trubusan membutuhkan pemanenan dan pemangkasan periodik untuk mencegah pemanjangan tunas yang berlebihan serta untuk mengatur struktur percabangan. Ditambahkan oleh Hartman et.al (1990), bahwa trubusan yang telah tua akan sulit untuk diakarkan. Pada dasarnya untuk 
produksi bahan klonal dapat dilakukan dengan memodifikasi areal hutan produksi dengan mengaplikasikan teknik seleksi pohon plus guna mendapatkan tanaman stok (sumber bahan klonal).

\section{KESIMPULAN}

1. Penambahan NAA $400 \mathrm{ppm}, 1200 \mathrm{ppm}$ dan $2400 \mathrm{ppm}$ meningkatkan keberhasilan persen stek berakar berturut-turut mulai dari $58,30 \%, 66,70 \%$ dan $92,30 \%$,

2. Dengan konsentrasi 4000 ppm memberikan indikasi penurunan kemampuan berakar $(84,93 \%)$.

3. Penggunaa konsentrasi NAA 1200 ppm terbukti mampu meningkatkan keberhasilan persen jadi stek G. arborea.

\section{DAFTAR PUSTAKA}

Balfas, J. 1995. Beberapa Aspek Teknologi pada Kayu Hasil Pengembangan Hutan Tanaman Industri (HTI) di Indonesia. Prosiding Diskusi Hasil-hasil Penelitian, Balai Penelitian Kehutanan Pematang Siantar Tahun 1995. Parapat.

Danu; M. Ihwan; D. Junaedi; O. Marom. 1991. Pertumbuhan Tanaman Jati Putih (Gmelina arborea) Hasil Biakan Vegetatif (stek) di Kebun Percobaan Rumpin Bogor. Silvatropika N0. 04 November 2001. Pp 3 - 5.

Gomez, K.A and A.A Gomez, 1984. Statistical Procedures for Agricultural Research. John Wiley and Sons. Inc. New York.

Hartman, N.M; D.E. Kester and F.T. Davies. 1990. Plant Propagation Principles and Practices. Prentice Hall Inc. Englewood Cliff. New Jersey. Pp 25 - 304.

Jayusman, 1997. Percobaan Stek Pucuk Kemenyan Durame (Styrax benzoine Dryand) pada Beberapa Jenis Hormon Pertumbuhan. Bulletin Balai Penelitian Kehutanan Sumatera. Volume 13(1): $79-92$.

Leakey, R.R.B; V.R. Chapman; K.A. Longman. 1982. Physiological Studies for Tree Improvement and Conservation, Factor Affecting Root Initiation in Cutting of Triplochiton scleroxylon $\mathrm{K}$. Schum, Forest Ecology and Management $4: 53$ - 56.

Longman, K.A. 1993. Rooting Cutting of Tropical Trees. Tropical Trees Propagation and Planting Manuals Volume 1. Common Wealth Science Council. Pp 9 - 117.

Shiembo P.N; A.C. Newton; R.R.B. Leakey. 1997. Vegetative Propagation of Rhicenodendron heudelotii. A West African Fruit Tree. Journal of Tropical Forest Science 9(4): 514 - 525.

Siagian N; D. Sitompul; A. Manurung. 1995. Effect of Auxin on the Root Growth in Hevea Marcottages. Indonesian Journal National Rubber Research, 13 (1): 21 - 31.

Sipayung, M. 1993. Metode Pengembangbiakan Vegetatif dalam Mendukung Program Pemuliaan Tanaman Gmelina arborea di PT Surya Hutani Jaya, Kalimantan Timur. Prosiding Lokakarya Pemuliaan dan Perbenihan Pohon Hutan Purwobinangun, 25 - 26 Agustus 1993. Pp 248 - 258.

Yasman, I and D. Leppe, 1992. Pertumbuhan Stek Gmelina arborea Roxb di Wanariset Samboja. Diskusi Hasil-Hasil Penelitian HTI. Badan Litbang Kehutanan Jakarta, 6 - 7 Mei 1992. Pp 1 - 5. 